\title{
Plasma Induced Changes in Human Lipid Composition as Revealed through XPS-Analysis
}

\author{
Joanna Hirschberg1,2, Leander Loewenthal' ${ }^{1}$, Alexander Krupp ${ }^{1}$, Steffen Emmert ${ }^{3}$, \\ Wolfgang Viöl1,2 \\ ${ }^{1}$ Department of Sciences and Technology, HAWK University of Applied Sciences and Arts, Göttingen, Germany \\ ${ }^{2}$ Fraunhofer Institute for Surface Engineering and Thin Films IST, Application Center for Plasma and Photonic \\ APP, Göttingen, Germany \\ ${ }^{3}$ Clinic for Dermatology and Venereology, University Medical Center Rostock, Rostock, Germany \\ Email: wolfgang.vioel@hawk-hhg.de
}

Received 25 January 2016; accepted 14 March 2016; published 17 March 2016

Copyright (C) 2016 by authors and Scientific Research Publishing Inc.

This work is licensed under the Creative Commons Attribution International License (CC BY). http://creativecommons.org/licenses/by/4.0/

(c) (i) Open Access

\begin{abstract}
In this study two plasma sources were used for an in vivo treatment of human stratum corneum. The sample preparation was realised with the Cyanoacrylat stripping method, whereby a few layers of corneocytes embedded in the lipid matrix were removed from the skin of healthy volunteers. For the plasma treatment, dielectric barrier discharges with pulse durations in the microsecond as well as in the nanosecond range were applied. A comparison of these sources with respect to their biologically active components including dissipated power, gas and electron temperature, irradiance in the ultraviolet range, ozone and nitric oxide concentration is presented. Furthermore, species generated during plasma treatment on the sample surface like hydrogen peroxide, nitride or nitrate were measured using reflectometry. In addition, safety aspects for both sources were evaluated. Resulting plasma induced changes in the sample composition were investigated through X-ray photoelectron spectroscopy. The main ingredients carbon, oxygen, and nitrogen in addition to minor concentrations of sulphur were considered. A significant influence of the pulse duration on plasma characteristics was shown. A more effective formation of reactive species as well as more intense UV emission for ns-plasma was observed. Based on the determined parameters, both plasma sources are suitable for therapeutic purpose. Furthermore, significant plasma induced changes in the stratum corneum composition were reported, including an increase in nitrogen and oxygen content.
\end{abstract}

\section{Keywords}

Dielectric Barrier Discharge, Plasma Medicine, Lipid-Stripping, XPS 


\section{Introduction}

Plasma medicine is a young, rapidly growing field of research, which has a high innovation potential due to the development of the so-called "cold plasma". A low gas temperature only a few degrees above room temperature, is characteristic for this cold plasma. Therefore, it is possible to apply a plasma treatment to temperature sensitive materials like human skin, seeds and plants, or wood surfaces [1]-[5]. The health system is continuously faced with new challenges, whereby the evaluation of alternative therapeutic approaches is essential. Especially in dermatology, the treatment of various skin diseases such as atopic dermatitis, ichthyosis or pathological dry skin is a problem since these clinical pictures are considered incurable; only the relief of symptoms can be achieved by intensive care. In this field, plasma devices for skin treatment offer new possibilities.

To improve wound healing especially in chronic wounds, as well as for stimulating regenerative processes, plasma devices are already used [1] [6] [7]. Thereby, a combination of different modes of action is utilised: a faster healing process is achieved through stimulation of the cell proliferation, and the antimicrobial effect of plasma treatment results in a reduction of the bacterial load in the wound [8]-[11]. The treated areas show an acidification which is persistent for several hours, and counteracting the renewed bacterial invasion [12]. Furthermore, anti-itching and anti-inflammatory effects were observed. Other studies show the direct treatment of atopic eczema with plasma, resulting in reduction of the itching, swelling and redness [13].

Additional application fields where new therapeutic/treatment methods could be validated are tooth treatment in dental medicine, sterilisation of surgical equipment, or veterinary medicine [14]-[16]. The treatment of melanoma was realised through plasma induced apoptosis of cancer cells without affecting neighbouring healthy cells [17]-[19].

Also, cold plasma is used for cosmetic treatment of nails [20] and skin [21]. For the latter method, a controlled damage of skin cells leading to a regeneration process of the upper layers of skin results in wrinkle improvement.

The effects of plasma treatment are based on a mixture of different biologically active components, including temperature, electric current, electric fields, UV-radiation, and reactive nitrogen (RNS) as well as reactive oxygen species (ROS). For many years, single components were already used for therapeutic purposes, taking into account permissible limits for each method not to be exceeded in order to avoid adverse effects.

The thermotherapy is a well-established method for the treatment of muscle tensions and pain, and is utilized to promote blood circulation. Additionally, the cell proliferation can be stimulated by a slight increase of temperature. Otherwise, temperatures above $318 \mathrm{~K}$ induce a denaturation and structural alteration of proteins [22]. For the therapeutic application of electric current in the mA-range, so-called iontophoretic transdermal systems were employed, whereby the drug delivery through the skin was increased [23]. Another application includes the stimulation of diseased nerves to slow down the associated degradation of affected muscle cells.

Positive impacts of radiation in the ultraviolet range on skin are anti-inflammatory and anti-itching properties, applied as part of phototherapy for treatment of psoriasis and eczema [24]. Too high doses of UV-radiation induce the generation of ROS in cells causing damaging of DNA, proteins, and lipids. Further consequences of excessive UV exposure are skin aging and an increased risk of skin cancer [22] [25] [26]. Thus, the International Commission on Non-Ionizing Radiation Protection (ICNIRP) gives guidelines for maximum radiation doses to prevent damage to skin [27].

There are diverse influences of ROS and RNS on the human organism. ROS provokes cell damage and cell death as well as defects in the respiratory system in high doses. In addition, the stimulation of cell proliferation, skin disinfection and an improved wound healing were observed [28]-[30]. Among other things, the RNS show an impact on blood coagulation and the immune system plus anti-microbial and anti-inflammation properties [31] [32]. In therapeutic use, concentration limit requirements must be complied: the German Research Foundation (DFG) or the German Social Accident Insurance (DGUV) define guidelines for maximum workspace concentrations for several reactive species which could be used here [33] [34].

During plasma treatment, all components act simultaneously on the substrate. Possible synergetic effects of these components could not be clarified sufficiently yet, but especially concerning the interaction of plasma with the complex structure and composition of skin, the knowledge of different mechanisms of action is the basis to validate new therapeutic approaches.

For this purpose, an in-vitro plasma treatment on Stratum Corneum (SC) was performed. The SC-samples were produced with the Cyanoacrylat Stripping Method and comprising corneocytes embedded in a lipid matrix 
including ceramides, cholesterol, and free fatty acids [35] [36]. For the direct treatment, dielectric barrier discharges were utilized. The study presented here is intended to provide insights in species formation in the discharge volume as well as on the sample surface. The concentrations of two reactive species, ozone and nitric oxide, were determined with the help of absorption spectroscopy. These species have an important impact on the human organism. By reflectometry measurements, the hydrogen peroxide, ammonium, nitrides, and nitrates were measured on the sample surface.

The influence of the duration of the exciting high voltage pulses on the formation of various species has been validated. Therefore, two plasma sources with comparable dissipated power, voltage amplitude and pulse repetition frequency, which only differ in the pulse duration ( $\mu$ - as well as ns-range) and in the resulting discharge current, were applied. The plasma devices have been characterized with respect to rotational, vibrational and electron temperature by high resolution optical emission spectroscopy in a previous study. Emission spectra and the additional use of a radiometer allow the calculation of the irradiance in the ultraviolet range. A spectral weighting factor of the ICNIRP allows the evaluation of the effective irradiance, taking into account the wavelength-depending effects of radiation on the skin. Plasma induced changes in skin samples were studied via X-ray photoelectron spectroscopy. For this purpose, the sample composition was examined before and after plasma treatment. The carbon, oxygen, nitrogen and sulphur content as well as the chemical bonds were investigated. Through this, conclusions about the structure-modifying effect of plasma treatment on SC may be drawn.

\section{Materials and Methods}

\subsection{Lipid Sample Preparation/Cyanoacrylate Stripping Method}

The lipids of the SC in combination with keratin form a closed-packed layer with great importance for the skin barrier function. The Cyanoacrylate Stripping method was applied for collecting non-invasive human SC. In the process, a drop of cyanoacrylate adhesive LiquiBand ${ }^{\circledR}$ (MedLogic Global Limited, Plymouth, United Kingdom) was placed on a sample holder, here an aluminium surface, pressed onto the skin and then removed after 60 seconds [35]. The previously cleaned forearms of healthy volunteers were used for sample collection. The samples have a homogeneous surface showing a representative composition of the SC. Samples prepared as above consist of corneocytes, which arise from keratinocytes transformed during epidermal differentiation, imbedded in the lipid matrix. The main ingredients of this matrix are ceramide, cholesterol and free fatty acids in equal shares [36]. A comparable heating of both skin and lipid-stripping samples as well as a similar acidifying effect on the substrates during plasma treatment were investigated. Moreover, a high absorption in the UV-range was detected [37]. Thus the lipid stripping could be utilized in our study for non-invasive preparation of skin models for plasma medical investigations.

\subsection{Dielectric Barrier Discharge Setup}

The applied plasma sources are based on the concept of dielectric barrier discharges. Both sources consist of the same electrode geometry, comprising a copper electrode covered by a ceramic $\left(\mathrm{Al}_{2} \mathrm{O}_{3}\right)$ cylinder. The wall thickness of the dielectric barrier is about $1 \mathrm{~mm}$. The discharges were ignited in ambient air at atmospheric pressure; the discharge gap was kept constant at $1 \mathrm{~mm}$. The lipid stripping samples were applied as grounded counter electrodes in the setup. The two plasma sources show a comparable dissipated power, voltage amplitude and pulse repetition frequency and only differ in the pulse duration ( $\mu$ s- as well as ns-range) and in the resulting discharge current. Additional plasma parameters such as rotational and electron temperature have already been investigated by high resolution spectroscopy, presented in Table 1 .

By using these plasma sources, it is possible to draw conclusions about the influence of the pulse duration on the resulting plasma parameters and consequently the impact on plasma induced changes in the treated samples. In various studies, DBDs with pulse durations in the ns-range were applied. This excitation mode results in a quasi-uniform discharge with less streamer formation, which does not require constant discharge gaps [39] [40]. In addition, a faster inactivation and thus a higher antimicrobial efficacy on large surfaces and in recessed areas could be shown [40] [41]. Therefore, the effects of ns-plasma on SC and benefits arising there from will be evaluated; furthermore safety aspects will be discussed. The detailed characterization of the plasma devices, which is continued in this study, is the basis for considering possible modes of action. 
Table 1. Plasma parameters [38].

\begin{tabular}{ccc}
\hline & $\mu s$-source & ns-source \\
\hline Peak voltage $U_{\max }$ & $11.6 \mathrm{kV}$ & $11.7 \mathrm{kV}$ \\
Pulse duration $t_{\text {pulse }}$ & $70 \mu \mathrm{s}$ & $600 \mathrm{~ns}$ \\
Pulse repetition rate $f$ & $300 \mathrm{~Hz}$ & $300 \mathrm{~Hz}$ \\
Dissipated power $P$ & $710 \mathrm{~mW}$ & $720 \mathrm{~mW}$ \\
Rotational temperature $T_{\text {rot }}=$ gas temperature $T_{\text {Gas }}$ & $375 \mathrm{~K}$ & $330 \mathrm{~K}$ \\
Mean electron energy $\varepsilon$ & $11 \mathrm{eV}$ & $8.25 \mathrm{eV}$ \\
Ozone concentration $c_{\mathrm{O}}$ & $275 \mathrm{ppm}$ & $1650 \mathrm{ppm}$ \\
Nitric oxide concentration $c_{\mathrm{NO}}$ & $580 \mathrm{ppm}$ & $2980 \mathrm{ppm}$ \\
Absolute irradiance $I$ & $42.5 \mathrm{~mW} / \mathrm{m}^{2}$ & $93.4 \mathrm{~mW} / \mathrm{m}^{2}$ \\
\hline
\end{tabular}

\subsection{Absorption Spectroscopy for Ozone and Nitric Oxide Measurements}

Amongst the numerous oxygen species generated into a plasma discharge, ozone was of particular interest due to its strong oxidative effect [29]. To investigate the concentration, the absorption spectroscopy based on the Lambert-Beer's Law was applied. For this purpose, the change in intensity in the absorption maximum of ozone at $254 \mathrm{~nm}$ was detected using quasimonochromatic radiation generated by low pressure mercury lamp TUV PL-S 9W/2P (Philips, Hamburg, Germany), the transmitted radiation is detected by a spectrometer AvaSpec3648-USB2 (Avantes BV, Apeldoorn, Netherlands). The declared values resulted from a sample size of five. In addition, the ozone-monitor 106-L (2B Technologies, Colorado, USA) was used, which makes it possible to study relative ozone concentrations at defined lateral distances from the discharge and, thus, to estimate the course of the ozone concentration beyond the discharge gap.

Nitric oxide is a well-known representative of the RNS in plasma discharges, which has an important varying impact on human organism [31] [32]. To study the production of nitric oxide, a self-developed measuring system [38] also based on absorption spectroscopy method was utilized. One resonance wavelength of nitric oxide at $226.2 \mathrm{~nm}$ was observed, by which the concentration inside the plasma volume could be investigated. The measurement method and the used setup are described in detail in [38]. The determination is based on ten datasets.

\subsection{UV-Irradiance}

The irradiance specifies the emitted power per area from a lighting source, in this case from a plasma discharge. In medical application, the emitted radiation in the UV-range has a primary importance, since its dose depending positive or negative effects on humans [24] [25]. The irradiance was recorded in the units $\mathrm{mW} / \mathrm{m}^{2}$ by applying the radiometer X1-1 (Gigahertz-Optik, Tuerkenfeld, Germany) and an absolute calibrated detector head UV3719-4a(z). The detector head was covered by a fused silica coated with a thin layer of indium tin oxide (ITO), which replaces the lipid stripping as counter electrode in the measurements (Figure 1).

The characteristics of ITO coated fused silica are a high transmission in the UV-range as well as the electrical conductivity, allowing the grounding of the glass electrode. The transmission function of the fused silica $T(\lambda)$ was measured spectroscopically and was included in the evaluation. Furthermore, emission spectra of the discharge $E(\lambda)$ were taken for calculating the spectrally resolved intensity distribution $I(\lambda)$ :

$$
I(\lambda)=E(\lambda) \cdot \frac{I_{\text {abs }}}{\int_{250 \mathrm{~nm}}^{400 \mathrm{~nm}} E(\lambda) \cdot T(\lambda) \mathrm{d} \lambda},
$$

where $I_{\text {abs }}$ is the absolute measured irradiance. The ICNIRP has given a spectral weighting factor $S(\lambda)$ taking into account the wavelength-dependent effect of electro-magnetic radiation on human skin [27]. Thus, an effective irradiance $I_{\text {eff }}$ can be determined by: 


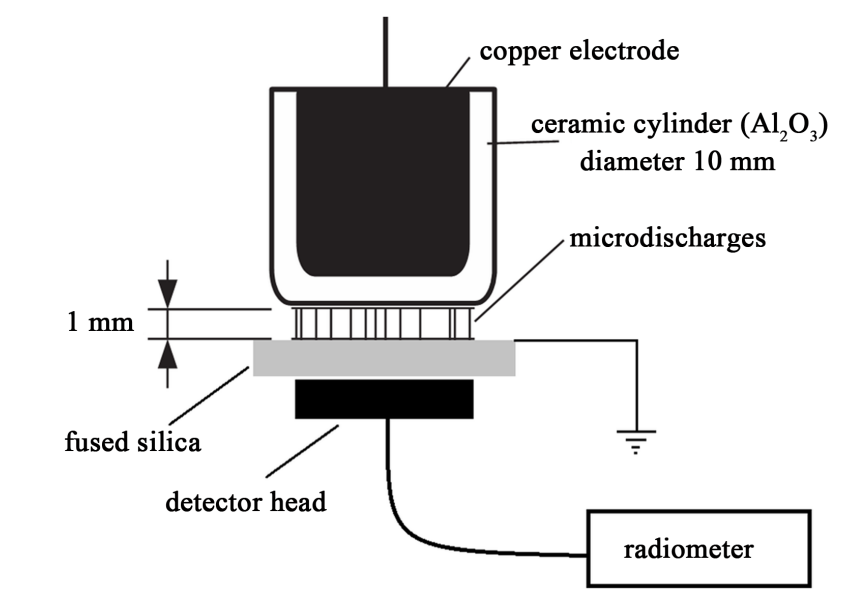

Figure 1. Experimental setup for radiometric measurements.

$$
I_{\text {eff }}=\int_{200 \mathrm{~nm}}^{400 \mathrm{~nm}} I(\lambda) \cdot S(\lambda) \mathrm{d} \lambda
$$

In addition, the ICNIRP releases policies with regard to maximum dosage of effective expose per day. The limit of $D_{\max }=30 \mathrm{~J} / \mathrm{m}^{2}$ was suggested for the most sensitive type of skin and enables the calculation of a safetylimited treatment duration $t_{\max }$ :

$$
t_{\max }=\frac{D_{\max }}{I_{\text {eff }}} .
$$

\subsection{Reflectometric Measurements}

In this study, the nitric $\left(\mathrm{NO}_{2}^{-}\right)$, nitrate $\left(\mathrm{NO}_{3}^{-}\right)$, hydrogen peroxide $\left(\mathrm{H}_{2} \mathrm{O}_{2}\right)$, and ammonium ( $\mathrm{NH}_{4}^{+}$) concentration on the sample surface before and after a 1 minute plasma treatment were investigated. All these reactive species were generated in the discharge and reach the sample surface, where chemical reactions take place afterwards. The plasma induced acidification of skin results from the nitrides and nitrates, rendering the formation of nitric and nitrous acid the assumed mechanism of surface acidification [12]. The pH controls essential functions of the skin, for example enzymes, which have a crucial role in the restoration of the barrier function. In addition, the bacterial colonization of the SC depends on the cutaneous $\mathrm{pH}$ [42]. The investigated hydrogen peroxide is a high chemically active agent and acts like a strong oxidant in the human body. It is a by-product of cellular metabolism and is formed by the oxidation of fatty acids, whereby peroxide is found as natural component in the epidermis. In organisms, it fulfils the function of an important neurotransmitter and is associated with the natural moistening factors. In high concentrations, peroxide has a cytotoxic effect [43]. The ammonium is generated in the human body by the degradation of proteins and amino acids. Due to its similarity to the potassium ion, ammonium can block potassium controlled synapses whereby it acts as a neurotoxin. Furthermore, $\mathrm{NH}_{4}$ induces apoptosis in cells [44] [45].

For measuring the concentrations of these species, a reflectometric measurement with the RQflex 10 (Merck KGaA, Darmstadt, Germany) and reflectometric test strips was realized. The chemical compounds to be investigated were dissolved indistilled water from the sample surface. In the case of nitric, nitrate, and hydrogen peroxide measurements a volume of $50 \mu \mathrm{l}$, in the case of ammonium measurement a volume of $100 \mu \mathrm{l}$ was required. The varying amounts of liquid arise from different manufacturer specifications on experimental procedure. The respective test strips were moisturized with the solution and the resulting change of colour was reflectometrically evaluated. The results presented here based on a sample size of five test persons with two samples each.

\subsection{X-Ray Photoelectron Spectroscopy}

X-ray photoelectron spectroscopy provides information about the elemental and chemical composition. In this study the carbon, oxygen and, nitrogen as well as the sulphur content of SC were investigated. Therefore, survey 
spectra from $0 \mathrm{eV}$ up to $1400 \mathrm{eV}$ as well as high resolution scans of the $\mathrm{C} 1 \mathrm{~s}$ (284.8 eV), O1s ( 532 eV), $\mathrm{N} 1 \mathrm{~s}$ $(\sim 400 \mathrm{eV})$, and the S2p ( 168 eV) peaks were taken. All binding energies of photoemission peaks were referenced to the $\mathrm{C} 1 \mathrm{~s}$ peak at $284.8 \mathrm{eV}$. For further information, a peak fitting with Gauss-Lorentzian profiles was performed on the high-resolution C1s spectra. The measurements were carried out on the XPS system PHI Versa Probe II (Physical Electronics, Inc., Minneapolis, USA) in high vacuum at $10^{-6} \mathrm{~Pa}$. The exciting line radiation was generated by means of a monochromatized $\mathrm{Al} \mathrm{K \alpha} \mathrm{X}$-ray source with a line width of $0.26 \mathrm{eV}$. The resolution of the system is $<0.5 \mathrm{eV}$.

Photoelectrons driven out from the sample, induced by the high energy X-rays, have characteristic kinetic energies that directly identify each element and chemical bond present in the sample surface. The investigations were accomplished with a spot diameter of $200 \mu \mathrm{m}$; the information depth of the measurements is less than tennanometres. For the analysis, the photoelectron peak areas were calculated after Shirley background correction. The peak fitting was performed using MultiPak Software (Ulvac-Phi, Inc., Minneapolis, USA). Three analyses were performed per test person (two volunteers in total) before and after the plasma treatment.

\section{Results and Discussion}

\subsection{Ozone and Nitric Oxide Concentration}

During the plasma treatment, several ROS and RNS were generated within the discharge volume. This paper is limited to the evaluation of two species, ozone and nitric oxide, because they are formed in high concentrations in the plasma discharge. Also, several effects of $\mathrm{O}_{3}$ and $\mathrm{NO}$ are already known in medical application, like regulation of wound healing, anti-inflammatory effects or the stimulation of proliferation [22]. These effects are of particular interest.

The ozone concentrations of both discharge sources are measured directly in the discharge. In the ns-plasma, a maximum concentration of approximately $1650 \pm 60$ ppm was determined, the $\mu$ s-plasma exhibits a six times lower value ( $275 \pm 30 \mathrm{ppm})$ despite the same dissipated power. These results are in line with the expected effective ozone generation in ns-discharges, which was already shown in [10]. Since both positive and negative characteristics of ozone in human organism are known, a careful consideration of the predetermined limit values is necessary to ensure a safe medical use. At this point, the limits of the DGUV were used, which classifies an 8 h mean of $60 \mathrm{ppb} \mathrm{O}_{3}\left(120 \mu \mathrm{g} / \mathrm{m}^{3}\right)$ as not dangerous to human health [34]. The measured concentrations directly in the discharge are significantly higher than the existing limits. Because the formation of reactive species is restricted to the discharge gap, the small plasma volume $\left(\sim 80 \mathrm{~mm}^{3}\right)$ results in small absolute amounts of produced ozone molecules. By mixing this species with ambient air, a rapid decrease in the concentration with increasing lateral distance from discharge can be assumed. Theoretically, the ozone concentration would decrease to $\sim 5 \mathrm{ppb}$ in case of $\mu$ s-plasma and $\sim 30 \mathrm{ppb}$ in case of ns-plasma at a lateral distance of $10 \mathrm{~cm}$ around the discharge (equivalent to a sphere volume of about $4190 \mathrm{~cm}^{3}$ ). This sharp drop could be confirmed by the studies carried out; an exponential decay of the concentration with increasing lateral distances was detected (data not shown).

Due to the experimental setup, the measurement of the NO concentration is only possible within the discharge. For the $\mu$ s-plasma a value of $580 \pm 70 \mathrm{ppm}$, for the ns-plasma a value of $2980 \pm 80 \mathrm{ppm}$ was detected. With regard to NO molecules the more efficient formation of reactive species in the ns-discharge was also confirmed, with a five times higher concentration. To evaluate these results with regard to safety aspects, the DFG guidelines specifying a maximum workplace concentration of $0.5 \mathrm{ppm}$ NO $\left(0.95 \mathrm{mg} / \mathrm{m}^{3}\right)$, based on an $8 \mathrm{~h}$ exposure time, are utilized [33]. Both discharges clearly exceed this limit. However, as mentioned before, the little discharge volume results in a small number of generated NO molecules mixing up with ambient air beyond the discharge gap. In a lateral distance of $5 \mathrm{~cm}$ around the discharge, equivalent to a sphere volume of approximately $500 \mathrm{~cm}^{3}$, the NO concentration would drop to $\sim 0.1 \mathrm{ppm}$ in case of $\mu$ s-plasma and $\sim 0.47$ ppm in case of nsplasma. These resulting concentrations are significantly below the DFG limit.

In summary, a safe use of the examined discharges is ensured, if the distance to the respiratory tract does not drop below $15 \mathrm{~cm}$, whereas the ozone concentration is the limiting factor. Also in the ns-discharge, a more efficient formation of reactive species is shown, and therefore major changes in the treated substrates were expected and proven by XPS (see Section 3.4).

\subsection{Irradiance in the UV-Range}

For determining the absolute irradiance $I_{\mathrm{abs}}$ in the substrate level, the UV radiation has been detected in a wave- 
length range of 250 - $400 \mathrm{~nm}$, whereby the detector head occupies the position of the treated substrates in the experimental setup. Thus, the results correspond to the irradiance that interacts with the sample surface during treatment. For the $\mu$ s-discharge a value of $42.5 \pm 0.2 \mathrm{~mW} / \mathrm{m}^{2}$ for ns-discharge a value of $93.4 \pm 10 \mathrm{~W} / \mathrm{m}^{2}$ was calculated; the given values are based on 10 individual measurements using the radiometer.

For the subsequent evaluation of the wavelength-dependent effect of the plasma radiation, the emission spectra of both sources (data not shown) were taken into account. The emitted radiation essentially depends on the working gas used; in discharges ignited in ambient air the high nitrogen content dominates the appearance of spectra resulting in a high emission in the UVA and low proportions of UVB. The harmful short wavelength UVC radiation is effectively absorbed by oxygen and nitrogen species, so that it does not interact with the biological substrates in treatment [46] [47]. According to Equation (1) with the help of emission spectra the spectrally resolved intensity distribution $I(\lambda)$ is calculated; by Equation (2) the spectral weighting factor $S(\lambda)$ is taken into account resulting in an effective irradiance of $2.3 \pm 0.01 \mathrm{~W} / \mathrm{m}^{2}$ ( $\mu$ s-source) and $3.7 \pm 0.4 \mathrm{~W} / \mathrm{m}^{2}$ (ns-source).

Based on ICNIRP guidelines with regard to the maximum effective irradiance dosage, a limit value for treatment duration of about $3.6 \mathrm{~h}$ in case of $\mu$ s-discharge, and $2.3 \mathrm{~h}$ in case of ns-discharge is determined. Consequently, lower treatment times must be complied for security reasons for ns-plasma. However, since typical exposure times in medical therapies are in the range of a few minutes, these results do not contradict dermatological applications of these plasma sources [6] [48]. In [49] discharges with a similar electrode geometry but significant lower dissipated power have been investigated resulting in maximum exposure times in the range of $6 \mathrm{~h}$. Based on this, a major influence of the dissipated power to the absolute irradiance can be assumed.

\subsection{Nitrite, Nitrate, Peroxide and Ammonium Species}

To estimate the interaction of the ROS and RNS with the SC formed in the plasma discharge, the occurring species concentrations on the sample surface were examined. For a comparison of the two discharge modes, the significance of the results was verified using the Student distribution (T-test). Prior to the plasma treatment, none of the tested chemical compounds could be detected on the lipid stripping; the concentrations immediately after plasma exposure are shown in Figure 2.

The nitric, peroxides and ammonium species were measured in a comparable concentration in the range of 0 $3 \mathrm{mg} / \mathrm{l}$, the nitrate concentrations are more than one order of magnitude higher. This result corresponds to our expectations, because in the here considered discharges $\mathrm{NO}_{\mathrm{x}}$ was formed by numerous reactions [50]. The low nitride content could be explained by the oxidation of this compound to the more stable nitrate. It can be assumed that the detected nitrate concentration originates from the almost completely dissociated nitric acid, which in turn is responsible for the acidifying effect of the plasma treatment [12].

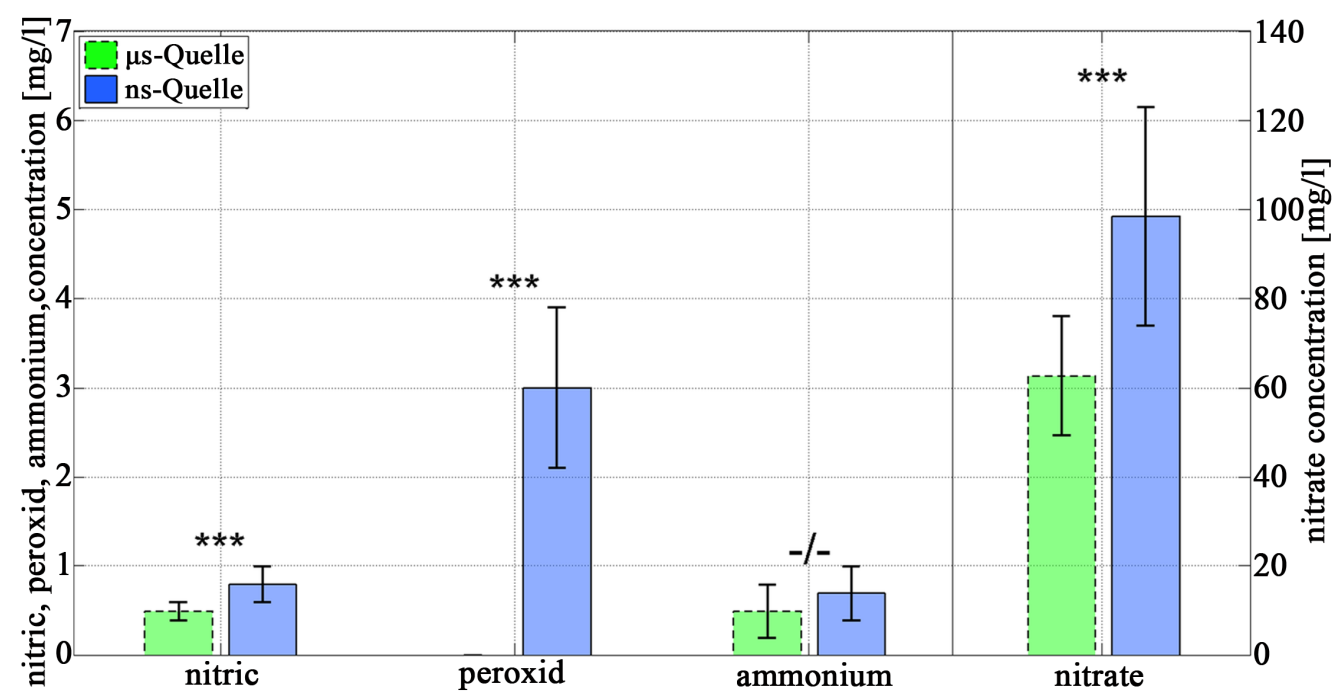

Figure 2. Nitric, peroxid and ammonium concentration (left y-axis) and nitrate concentration (right y-axis) on the lipid sample surface after 60 seconds of plasma treatment; statistical significant differences between the two plasma sources are marked with *** $(p \leq 0.001),-/-(p>0.05)$. 
The ammonium and peroxide concentration on the substrate show very low concentrations, so harmful effects to human skin are not expected. Furthermore, the SC represents an effective barrier; cytotoxic effects of the substances are only possible in the living cells in the epidermis. On the other hand, the antiseptic and antibacterial properties of low concentrations of $\mathrm{H}_{2} \mathrm{O}_{2}$ are well known [51]. This effect can be expected even after a plasma treatment of skin, which contributes the wound healing enhancing properties of the plasma therapy.

Analogous to the ozone and nitric oxide formation, a more efficient generation of the species by the ns-plasma is shown as well. Excluding the $\mathrm{NH}_{4}$, which has no significant statistical differences due to very large fluctuations, the measured values show differences between the two plasma sources with a significance level of $p \leq 0.0001$. As well the detected nitrate concentrations are confirmed with the stronger acidifying effect of ns-plasma [37]. An abnormality in the results is the undetectable $\mathrm{H}_{2} \mathrm{O}_{2}$ content after $\mu$ s-plasma treatment; this result could not be sufficiently clarified yet. In addition, it cannot be excluded that the resulting concentrations are below the detection limit of $0.2 \mathrm{mg} / \mathrm{l}$.

\subsection{Plasma Induced Changes Examined by XPS}

For the evaluation of plasma induced changes in SC-compositions, carbon, oxygen and nitrogen contents of untreated and plasma-treated samples were examined. In Figure 3, an XPS survey spectrum, recorded in the range of 0 to $1400 \mathrm{eV}$, is presented exemplary. The measured surface compositions are given in Table 2.

It is already known that using the Cyanoacrylate Stripping method for SC-samples preparation results in a lipid covered sample surface. This effect is based on cohesive fractures within the lipid bilayer occurring during sample extraction [52]. This finding could be confirmed by the detected composition of untreated SC-surfaces. Proteins as part of corneocytes show significant differences in formulation compared with lipids (see Table 2). The calculated stoichiometry of the reference corresponds well with the expected composition for skin lipids.

After plasma treatment, a clear increase in oxygen and nitrogen content as well as a decrease of carbon content was shown, independent of the used DBD. This observation can be caused by two plasma induced effects: 1) The ROS and RNS present in plasma lead to an oxidation and nitration or rather nitrosation in the SC whereby oxygen and nitrogen are included in the sample; 2) The plasma treatment removes surface lipids by which the underlying corneocytes were detected. A purification of surfaces by plasma induced ablation was already shown inter alia by Iwasaki et al. [53].

In detail, the plasma induced changes were analysed on the basis of the carbon 1s peak. In Figure 4, a C1s detail spectrum of untreated and ns-treated SC is depicted. A significant increase in C-N, C-O, N-C=O and $\mathrm{O}-\mathrm{C}=\mathrm{O}$ bonds as well as a reduction of $\mathrm{C}-\mathrm{C}$ bonds were detectable after $1 \mathrm{~min}$ plasma treatment. This result is in line with the expectations based on the previously discussed changes in stoichiometric ratios.

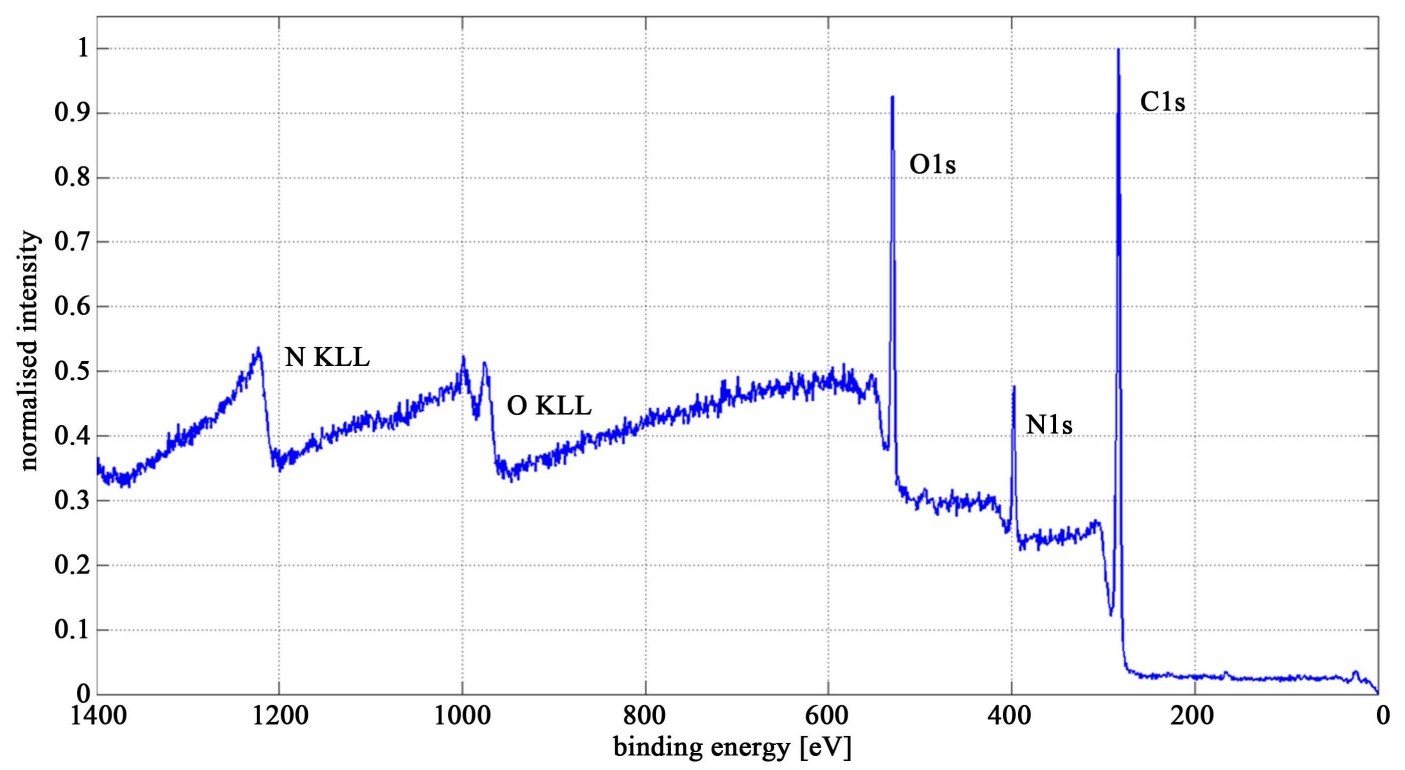

Figure 3. XPS survey spectrum of untreated SC. 


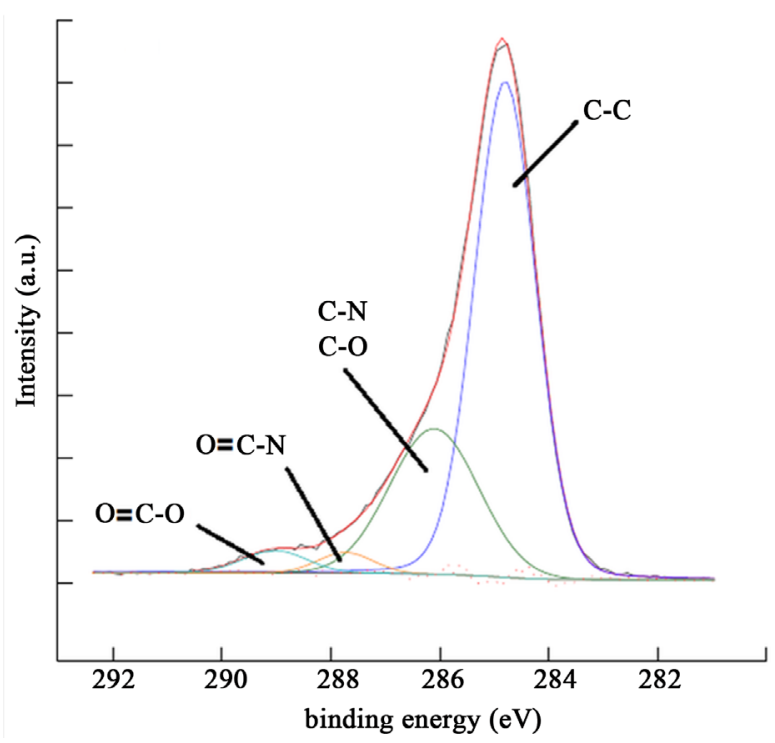

(a)

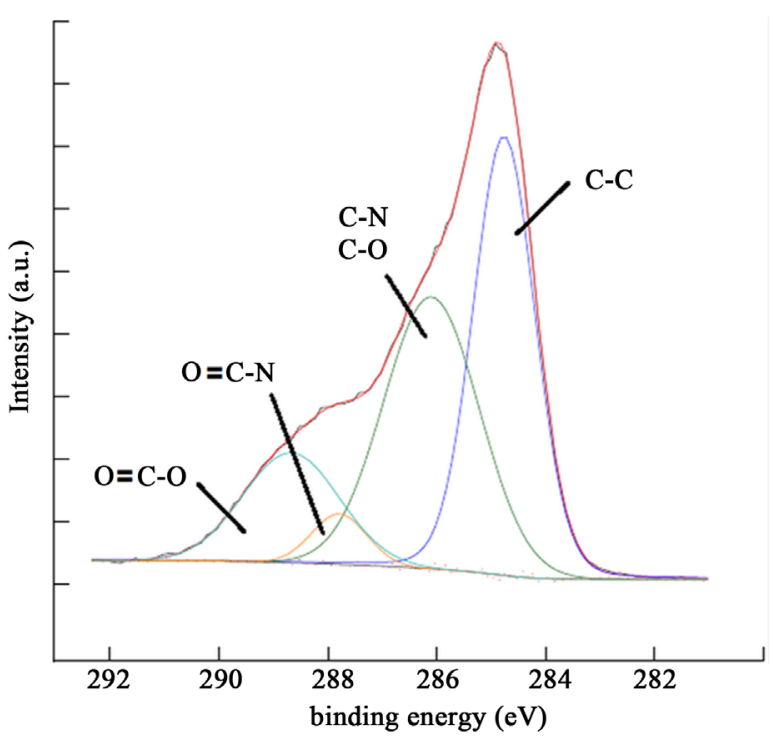

(b)

Figure 4. C1s detail spectrum of (a) untreated SC and (b) ns-treated SC: black line-measured spectra; red line-mathematical fit; red dots-deviations.

Table 2. XPS-determined atomic concentrations (atom \%) in SC-samples as well as values for protein- and skin lipid-composition from literature [52] [54].

\begin{tabular}{ccccc}
\hline & C1s & N1s & O1s & S2p \\
\hline Reference & $89.9 \pm 1.5$ & $2.3 \pm 0.6$ & $7.8 \pm 1.2$ & - \\
Ms-plasma & $75.4 \pm 2.6$ & $6.2 \pm 1.2$ & $18.3 \pm 3.0$ & $0.2 \pm 0.1$ \\
ns-plasma & $73.8 \pm 2.4$ & $8.5 \pm 0.9$ & $17.5 \pm 1.5$ & $0.3 \pm 0.1$ \\
Protein & 59.9 & 23 & 17.1 & Not specified \\
Skinlipid & 90.9 & 0.23 & 8.5 & Not specified \\
\hline
\end{tabular}

As additional effect, small amounts of sulphur were found after the plasma treatment. In the reference, the S2p peak could not be clearly distinguished from noise in the signal. In human skin, two chemical bonds of sulphur are known, on the one hand in the form of $\mathrm{S}^{\mathrm{IV}}$ (sulphate) as component in cholesterol sulphate, on the other hand in form of $\mathrm{S}^{\mathrm{II}}$ which can be found in disulphide bridges of proteins [54]. Whereas it is assumed that in the uppermost layer of the skin $\mathrm{S}^{\mathrm{IV}}$ can also be found as oxidised disulphide bonds [54]. Following the plasma treatment, both chemical bonds are verified, whereby the majority of the signal is caused by $\mathrm{S}^{\mathrm{IV}}$. Since no sulphur is expected to be introduced into the sample through the plasma treatment, this effect could also be explained by on the removal of surface lipids. Uncovering the corneocytes, the proportion of signalling disulphide bridges rises. Due to the oxidizing effect of plasma, mainly $\mathrm{S}^{\mathrm{IV}}$ is detected.

When comparing the two plasma sources, only minor differences in the composition are shown, although in case of ns-plasma a stronger impact is suspected due to the more effective formation of reactive species. As mentioned before, the plasma treatment leads to a mechanical removal of surface lipids. Consequently, it is assumed that the altered composition caused by the lipid removal overlays the plasma-induced changes and therefore no significant differences between $\mu$ s- and ns-discharge sources could be shown.

\section{Conclusions}

In this article, two DBD sources developed for medical use which only differ in the pulse duration ( $\mu$ s- as well as ns-range) and in the resulting discharge current were used for in-vitro plasma treatment of SC-lipids. A significant influence of the pulse duration on characteristics of the discharge was shown, including a more effective 
formation of reactive species in ns-plasma. The same dissipated power results in substantial higher ozone and nitric oxide concentrations when using pulse durations in the ns-range. This behaviour is also confirmed by the reactive oxygen and nitrogen species generated on the sample surface. In addition, the ns-source emits a two times higher irradiance in the UV-range.

A safety evaluation was performed based on the determined parameters ozone, nitric oxide and UV-irradiance. No harmful effects are expected as long as the minimal distance between the discharge gap and the respiratory tract is more than $15 \mathrm{~cm}$, and if a maximum application time of $2 \mathrm{~h}$ is not exceeded. However, this limitation in treatment time is practically irrelevant since positive therapeutic effects were achieved after only a few minutes of plasma treatment in previous clinical studies [6] [48].

Plasma induced changes in the SC-composition were detected by means of XPS with regard to carbon, oxygen, and nitrogen content. A marked increase in oxygen and nitrogen content in plasma treated SC-samples was detected which can be explained by oxidation, nitrosation, and nitration of the sample surface as well as a removal of surface lipids by plasma treatment.

In summary, a major impact of pulse duration on the plasma composition was shown. With this parameter, the biological active components can be dimensioned for an individual therapeutic purpose.

\section{Acknowledgements}

This work was funded by the German Federal Ministry of Education and Research (BMBF), "PlasBaWirk", Contract No. 03FH015IX5.

\section{References}

[1] Awakowicz, P., Bibinov, N., Born, M., Busse, B., Gesche, R., Helmke, A., Kaemling, A., Kolb-Bachofen, V., Kovacs, R., Kuehn, S., Liebmann, J., Mertens, N., Niemann, U., Oplaender, C., Porteanu, H.-E., Scherer, J., Suschek, C., Vioel, W. and Wandke, D. (2009) Biological Stimulation of the Human Skin Applying Health Promoting Light and Plasma Sources. Contributions to Plasma Physics, 49, 641-647. http://dx.doi.org/10.1002/ctpp.200910068

[2] Avramidis, G., Stüwe, B., Wascher, R., Bellmann, M., Wieneke, S., Tiedemann, A. and Viöl, W. (2010) Fungicidal Effects of an Atmospheric Pressure Gas Discharge and Degradation Mechanisms. Surface \& Coatings Technology, 205, 405-408. http://dx.doi.org/10.1016/j.surfcoat.2010.08.141

[3] Fridman, G., Shereshevsky, A., Peddinghaus, M., Gutsol, A., Vasilets, V., Brooks, A., Balasubramanian, M., Friedman, G. and Fridman, A. (2006) Bio-Medical Applications of Non-Thermal Atmospheric Pressure Plasma. AIAA Plasma Dynamics and Laser Conference, San Francisco, 37.

[4] Wascher, R., Avramidis, G., Vetter, U., Damm, R., Peters, F., Militz, H. and Viöl, W. (2014) Plasma Induced Effects within the Bulk Material of Wood Veneers. Surface and Coatings Technology, 259, 62-67. http://dx.doi.org/10.1016/j.surfcoat.2014.07.005

[5] Wascher, R., Schulze, N., Avramidis, G., Militz, H. and Viöl, W. (2014) Increasing the Water Uptake of Wood Veneers through Plasma Treatment at Atmospheric Pressure. European Journal of Wood and Wood Products, 72, 685687. http://dx.doi.org/10.1007/s00107-014-0815-7

[6] Brehmer, F., Haenssle, H.A., Daeschlein, G., Ahmed, R., Pfeiffer, S., Görlitz, A., Simon, D., Schön, M.P., Wandke, D. and Emmert, S. (2015) Alleviation of Chronic Venous Leg Ulcers with a Hand-Held Dielectric Barrier Discharge Plasma Generator (PlasmaDerm ${ }^{\circledR}$ VU-2010): Results of a Monocentric, Two-Armed, Open, Prospective, Randomized and Controlled Trial (NCT01415622). European Academy of Dermatology and Venereology, 29, 148-155. http://dx.doi.org/10.1111/jdv.12490

[7] Fridman, G., Friedman, G., Gutsol, A., Shekhter, A.B., Vasilets, V.N. and Fridman, A. (2008) Applied Plasma Medicine. Plasma Processes and Polymers, 5, 503-533. http://dx.doi.org/10.1002/ppap.200700154

[8] Dobrynin, D., Fridman, G., Friedman, G. and Fridman, A. (2009) Physical and Biological Mechanisms of Direct Plasma Interaction with Living Tissue. New Journal of Physics, 11, Article ID: 115020. http://dx.doi.org/10.1088/1367-2630/11/11/115020

[9] Helmke, A., Hoffmeister, D., Berge, F., Emmert, S., Laspe, P., Merten, N., Viöl, W. and Weltmann, K.-D. (2011) Physical and Microbiological Characterisation of Staphylococcus epidermidis Inactivation by Dielectric Barrier Discharge Plasma. Plasma Processes and Polymers, 8, 278-286. http://dx.doi.org/10.1088/1367-2630/11/11/115020

[10] Mertens, N., Mahmoodzada, M., Helmke, A., Grünig, P., Laspe, P., Emmert, S. and Viöl, W. (2014) Inactivation of Microorganisms Using Cold Atmospheric Pressure Plasma with Different Temporal Discharge Characteristics. Plasma Processes and Polymers, 11, 910-920. http://dx.doi.org/10.1002/ppap.201300184

[11] Edwards, R. and Harding, G. (2004) Bacteria and Wound Healing. Current Opinion in Infectious Diseases, 17, 91-96. 
http://dx.doi.org/10.1097/00001432-200404000-00004

[12] Helmke, A., Hoffmeister, D., Mertens, N., Emmert, S., Schütte, J. and Viöl, W. (2009) The Acidification of Lipid Film Surfaces by Non-Thermal DBD at Atmospheric Pressure in Air. New Journal of Physics, 11, Article ID: 115025. http://dx.doi.org/10.1088/1367-2630/11/11/115025

[13] Mertens, N., Helmke, A., Goppold, A., Emmert, S., Kämling, A. and Wandke, D. (2009) Low Temperature Plasma Treatment of Biological Tissue. $2^{\text {nd }}$ International Conferences for Plasma Medicine, San Antonio.

[14] Sladek, R.E., Stoffels, E., Walraven, R., Tielbeek, P.J. and Koolhoven, R. (2004) Plasma Treatment of Dental Cavities: a Feasibility Study. IEEE Transactions on Plasma Science, 32, 1540-1543. http://dx.doi.org/10.1109/TPS.2004.832636

[15] Venezia, R.A., Orrico, M., Houston, E., Yin, S.M. and Naumova, Y.Y. (2008) Lethal Activity of Nonthermal Plasma Sterilization against Microorganisms. Infection Control \& Hospital Epidemiology, 29, 430-436. http://dx.doi.org/10.1086/588003

[16] Kramer, A., Lademann, J., Bender, C., Sckell, A., Hartmann, B., Münch, S., Hinz, P., Ekkernkamp, A., Matthes, R., Koban, I., Partecke, I., Heidecke, C.D., Masur, K., Reuter, S., Weltmann, K.D., Koch, S. and Assadian, O. (2013) Suitability of Tissue Tolerable Plasmas (TTP) for the Management of Chronic Wounds. Clinical Plasma Medicine, 1, 11-18. http://dx.doi.org/10.1016/j.cpme.2013.03.002

[17] Fridman, G., Shereshevsky, A., Jost, M., Brooks, A., Fridman, A., Gutsol, A., Vasilets, V. and Friedman, G. (2007) Floating Electrode Dielectric Barrier Discharge Plasma in Air Promoting Apoptotic Behavior in Melanoma Skin Cancer Cell Lines. Plasma Chemistry and Plasma Processing, 27, 163-176. http://dx.doi.org/10.1007/s11090-007-9048-4

[18] Keidar, M., Shashurin, A., Volotskova, O., Stepp, M.A., Srinivasan, P., Sandler, A. and Trink, B. (2013) Cold Atmospheric Plasma in Cancer Therapy. Physics of Plasmas, 20, Article ID: 057101. http://dx.doi.org/10.1063/1.4801516

[19] Vandamme, M., Robert, E., Lerondel, S., Sarron, V., Ries, D., Dozias, S., Sobilo, J., Gosset, D., Kieda, C., Legrain, B., Pouvesle, J.-M., Pape, A.L., et al. (2012) ROS Implication in a New Antitumor Strategy Based on Non-Thermal Plasma. International Journal of Cancer, 130, 2185-2194. http://dx.doi.org/10.1002/ijc.26252

[20] Kaemling, C., Kaemling, A., Tümmel, S. and Viöl, W. (2005) Plasma Treatment on Finger Nails Prior to Coating with a Varnish. Surface and Coatings Technology, 200, 668-671. http://dx.doi.org/10.1016/j.surfcoat.2005.01.065

[21] Foster, K.W., Moy, R.L. and Fincher, E.F. (2008) Advances in Plasma Skin Regeneration. Journal of Cosmetic Dermatology, 7, 169-179. http://dx.doi.org/10.1111/j.1473-2165.2008.00385.x

[22] Tiede, R., Hirschberg, J., Daeschlein, G., Woedtke, T., Viöl, W. and Emmert, S. (2014) Plasma Applications: A Dermatological View. Contributions to Plasma Physics, 54, 118-130. http://dx.doi.org/10.1002/ctpp.201310061

[23] Herndon, C.M. (2007) Iontophoretic Drug Delivery System: Focus on Fentanyl. Pharmacotherapy, 27, 745-754. http://dx.doi.org/10.1592/phco.27.5.745

[24] Weichenthal, M. and Schwarz, T. (2005) Phototherapy: How Does UV Work? Photodermatology, Photoimmunology \& Photomedicine, 21, 260-266. http://dx.doi.org/10.1111/j.1600-0781.2005.00173.x

[25] Merle, C., Laugel, C. and Baillet-Guffroy, A. (2010) Effect of UVA or UVB Irradiation on Cutaneous Lipids in Films or in Solution. Photochemistry and Photobiology, 86, 553-562. http://dx.doi.org/10.1111/j.1751-1097.2009.00690.x

[26] Matsumura, Y. and Ananthaswamy, H.N. (2004) Toxic Effects of Ultraviolet Radiation on the Skin. Toxicology and Applied Pharmacology, 195, 298-308. http://dx.doi.org/10.1016/j.taap.2003.08.019

[27] ICNIRP (2004) Guidelines on Limits of Exposure to Ultraviolet Radiation of Wavelengths between $180 \mathrm{~nm}$ and 400 nm (Incoherent Optical Radiation). Health Physics, 87, 171-186. http://dx.doi.org/10.1097/00004032-200408000-00006

[28] Paal, J.V., Verlackt, C.C., Yusupov, M., Neyts, E.C. and Bogaerts, A. (2015) Structural Modification of the Skin Barrier by OH Radicals: A Reactive Molecular Dynamics Study for Plasma Medicine. Journal of Physics D: Applied Physics, 48, Article ID: 155202. http://dx.doi.org/10.1088/0022-3727/48/15/155202

[29] Valacchi, G., Fortino, V. and Bocci, V. (2005) The Dual Action of Ozone on the Skin. British Journal of Dermatology, 153, 1096-1100. http://dx.doi.org/10.1111/j.1365-2133.2005.06939.x

[30] Martinez-Sanchez, G., Al-Dalain, S.M., Menendez, S., Re, L., Giuliani, A., Candelario-Jalil, E., Alvarez, H., Fernandez-Montequin, J.I. and Leon, O.S. (2005) Therapeutic Efficacy of Ozone in Patients with Diabetic Foot. European Journal of Pharmacology, 523, 151-161. http://dx.doi.org/10.1016/j.ejphar.2005.08.020

[31] Heuer, K., Hoffmanns, M.A., Demir, E., Baldus, S., Volkmar, C.M., Röhle, M., Fuchs, P.C., Awakowicz, P., Suschek, C.V. and Opländer, C. (2015) The Topical Use of Non-Thermal Dielectric Barrier Discharge (DBD): Nitric Oxide Related Effects on Human Skin. Nitric Oxide, 44, 52-60. http://dx.doi.org/10.1016/j.niox.2014.11.015

[32] Hu, H., Liang, H., Li, J., Zhao, Q. and He, J. (2007) Study on Production of Inhaled Nitric Oxide for Medical Applications by Pulsed Discharge. IEEE Transactions on Plasma Science, 35, 619-625. http://dx.doi.org/10.1109/TPS.2007.896782 
[33] German Research Foundation (2015) MAK Collection for Occupational Health and Safety. Wiley-VCH, Weinheim. http://dx.doi.org/10.1002/9783527694983

[34] Pflaumbaum, W., Hahn, N., Kolk, A., Liedtke, M., Maue, J., Rissler, J., Kaulbars, U., Heyden, T., Schwaß, D., Wittlich, M., Börner, F., Zilligen, H., Post, M. and Mewes, O. (2015) Limit Value List 2015. German Social Accident Insurance, Berlin, Germany.

[35] Jungersted, J., Hellgren, L., Drachmann, T., Jemec, G. and Agner, T. (2010) Validation of Cyanoacrylate Method for Collection of Stratum Corneum in Human Skin for Lipid Analysis. Skin Pharmacology and Physiology, 23, 62-67. http://dx.doi.org/10.1159/000265676

[36] Groen, D., Gooris, G.S. and Bouwstra, J.A. (2009) New Insights into the Stratum Corneum Lipid Organization by X-Ray Diffraction Analysis. Biophysical Journal, 97, 2242-2249. http://dx.doi.org/10.1016/j.bpj.2009.07.040

[37] Hirschberg, J., Gerhard, C., Braun, A., Grottker, S., Krupp, A., Emmert, S. and Viöl, W. (2015) Validation of the Suitability of Stripped Lipid as a Skin Model in Plasma Medical Investigations. Open Journal of Applied Sciences, 5, 40-49. http://dx.doi.org/10.4236/ojapps.2015.52005

[38] Peters, F., Hirschberg, J., Mertens, N., Wieneke, S. and Viöl, W. (2016) Plasma Science and Technology, in press.

[39] Hirschberg, J., Omairi, T., Mertens, N., Helmke, A., Emmert, S. and Viöl, W. (2013) Influence of Excitation Pulse Duration of Dielectric Barrier Discharges on Biomedical Applications. Journal of Physics D: Applied Physics, 46, Article ID: 165201. http://dx.doi.org/10.1088/0022-3727/46/16/165201

[40] Ayan, H., Staak, D., Fridman, G., Gutsol, A., Mukhin, Y., Starikovskii, A., Fridman, A. and Friedman, G. (2009) Application of Nanosecond-Pulsed Dielectric Barrier Discharge for Biomedical Treatment of Topographically Non-Uniform Surfaces. Journal of Physics D: Applied Physics, 42, Article ID: 125202. http://dx.doi.org/10.1088/0022-3727/42/12/125202

[41] Helmke, A., Grünig, P., Fritz, U.-M., Wandke, D., Emmert, S., Petersen, K. and Viöl, W. (2012) Low-Temperature Plasma-A Prospective Microbicidal Tool. Recent Patents on Anti-Infective Drug Discovery, 7, 223-230. http://dx.doi.org/10.2174/157489112803521995

[42] Hachem, J.-H., Man, M.-Q., Crumrine, D., Uchida, Y., Brown, B.E., Rogiers, V., Roseeuw, D., Feingold, K.R. and Elias, P.M. (2005) Sustained Serine Proteases Activity by Prolonged Increase in pH Leads to Degradation of Lipid Processing Enzymes and Profound Alterations of Barrier Function and Stratum Corneum Integrity. Journal of Investigative Dermatology, 125, 510-520. http://dx.doi.org/10.1111/j.0022-202X.2005.23838.X

[43] Zuliani, T., Denis, V., Noblesse, E., Schnebert, S., Andre, P., Dumas, M. and Ratinaud, M.-H. (2005) Hydrogen Peroxide-Induced Cell Death in Normal Human Keratinocytes Is Differentiation Dependent. Free Radical Biology and Medicine, 38, 307-316. http://dx.doi.org/10.1016/j.freeradbiomed.2004.09.021

[44] Matsuoka, M., Igisu, H., Kohriyama, K. and Inoue, N. (1991) Suppression of Neurotoxicity of Ammonia by L-Carnitine. Brain Research, 567, 328-331. http://dx.doi.org/10.1016/0006-8993(91)90814-C

[45] Buzanska, L., Zablocka, B., Dybel, A., Domanska-Janik, K. and Albrecht, J. (2000) Delayed Induction of Apoptosis by Ammonia in C6 Glioma Cells. Neurochemistry International, 37, 287-297. http://dx.doi.org/10.1016/S0197-0186(00)00030-9

[46] Yoshino, K., Parkinson, W.H., Ito, K. and Matsui, T. (2005) Absolute Absorption Cross-Section Measurements of Schumann-Runge Continuum of $\mathrm{O}_{2}$ at 90 and 295 K. Journal of Molecular Spectroscopy, 229, 238-243. http://dx.doi.org/10.1016/j.jms.2004.08.020

[47] Chang, W.F., Cooper, G., Sodhi, R.N.S. and Brion, C.E. (1993) Absolute Optical Oscillator Strengths for Discrete and Continuum Photoabsorption of Molecular Nitrogen (11 - 200 eV). Chemical Physics, 170, 81-97. http://dx.doi.org/10.1016/0301-0104(93)80095-Q

[48] Isbary, G., Heinlin, J., Shimizu, T., Zimmermann, J.L., Morfill, G., Schmidt, H.-U., Monetti, R., Steffes, B., Bunk, W., Li, Y., Klaempfl, T., Karrer, S., Landthaler, M. and Stolz, W. (2012) Successful and Safe Use of 2 min Cold Atmospheric Argon Plasma in Chronic Wounds: Results of a Randomized Controlled Trial. British Journal of Dermatology, 167, 404-410. http://dx.doi.org/10.1111/j.1365-2133.2012.10923.x

[49] Helmke, A., Wandke, D., Mahmoodzada, M., Weltmann, K.-D. and Viöl, W. (2013) Impact of Electrode Design, Supply Voltage and Interelectrode Distance on Safety Aspects and Characteristics of a Medical DBD Plasma Source. Contributions to Plasma Physics, 53, 623-638. http://dx.doi.org/10.1002/ctpp.201200133

[50] Kossyi, I.A., Kostinsky, A.Y., Matveyev, A.A. and Silakov, V.P. (1992) Kinetic Scheme of the Non-Equilibrium Discharge in Nitrogen-Oxygen Mixtures. Plasma Sources Science and Technology, 1, 207-220. http://dx.doi.org/10.1088/0963-0252/1/3/011

[51] Sobotta, M.C., Liou, W., Stöcker, S., Talwar, D., Oehler, M., Ruppert, T., Scharf, A.N.D. and Dick, T.P. (2015) Peroxiredoxin-2 and STAT3 Form a Redox Relay for $\mathrm{H}_{2} \mathrm{O}_{2}$ Signaling. Nature Chemical Biology, 11, 64-70. http://dx.doi.org/10.1038/nchembio.1695 
[52] Chen, Y.-L. and Wiedmann, T.S. (1996) Human Stratum Corneum Lipids Have a Distorted Orthorhombic Packing at the Surface of Cohesive Failure. Journal of Investigative Dermatology, 107, 15-19. http://dx.doi.org/10.1111/1523-1747.ep12296521

[53] Iwasaki, M., Matsudaira, Y., Takeda, K., Ito, M., Miyamoto, E., Yara, T., Uehara, T. and Hori, M. (2008) Roles of Oxidizing Species in a Nonequilibrium Atmospheric-Pressure Pulsed Remote $\mathrm{O}_{2} / \mathrm{N}_{2}$ Plasma Glass Cleaning Process. Journal of Applied Physics, 103, Article ID: 023303. http://dx.doi.org/10.1063/1.2830982

[54] Bahl, M.K. (1985) ESCA Studies on Skin Lipid Removal by Solvents and Surfactants. Journal of the Society of Cosmetic Chemists, 36, 287-296. 